\title{
Design of Auto-tuning Relay Feedback controller for Shell Heavy Oil Fractionator
}

\author{
Wahyudi $^{1, *}$, Sela Martasia ${ }^{1}$, Budi Setiyono ${ }^{1}$, and Iwan Setiawan ${ }^{1}$ \\ ${ }^{1}$ Control Laboratory, Department of Electrical Engineering, Diponegoro University, Semarang 50271, \\ Indonesia
}

\begin{abstract}
Auto-tuning relay feedback is one of the control techniques, which is used to solve the non-linear, long delay time, and disturbance's problems. This control technique is the development of Ziegler-Nichols that can be done automatically without doing system modeling. In this paper, auto-tuning relay feedback is used in the control system response to optimization of Shell Heavy Oil Fractionator (SHOF) system so the output of product composition as expected. SHOF is a distillation column type used to separate crude oil into desired products based on the difference in the boiling point of each product. PI regulators of relay feedback are used to control the valves on the SHOF with three inputs and three outputs that has been decoupled. Based on the tests, the average values of IAE at top end point composition $\left(\mathrm{Y}_{1}\right)$ obtained with disturbance and no disturbance are 83.17 and 10.933, respectively. At the side end point composition $\left(\mathrm{Y}_{2}\right)$, the average values of IAE with disturbance and no disturbance are obtained respectively, 336.38 and 42.3467 . The average values of IAE at bottom reflux temperature $\left(\mathrm{Y}_{3}\right)$ with disturbance and no disturbance are obtained 0.15 and 0.13 , respectively.
\end{abstract}

\section{Introduction}

Shell Heavy Oil Fractionator (SHOF) is a of distillation column type used to separate crude oil into desired products based on the difference in the boiling point of each product $[1,2]$. The design of control on SHOF has several constraints, it caused by nonlinearity of the process, multivariable interactions, long dead time, and disturbances. It needs a control method that is able to the control system response to optimization of SHOF system so the output of product composition as expected.

Previous research that relating to the control of SHOF is suggested that the combination of Subspace Identification Method (SIM). The Multivariable Output Error State Space (MOESP) method is adopted in SIM. This SIM-based double-layered is illustrated through an example of the heavy oil fractionator model[3]. Chunqing Huang and Shifu Chen used performance assessment of multi input multi output (MIMO) systems in the presence of plant uncertainty. It shows that only delay matrix is required, and the benchmark is obtained without any knowledge of interact matrix or Markov parameter matrices when condition regarding the delay matrix is satisfied. Effectiveness of this technique is

*Corresponding author: wahyuditinom@elektro.undip.ac.id 
demonstrated by the SHOF gain is uncertain[4]. Relay feedback that illustrated using the Ogunnaike Ray (OR) distillation column model is carried out on MIMO system. The model parameters thus obtained can be used to develop model based control schemes[5]. Autotuning relay feedback based design of fractional order PI controller for 2-by-2 MIMO system is performed on a Wood and Berry (WB) distillation column. The performance was measured by using Integral of Time and Absolute Error (ITAE)[6].

This paper proposed design of auto-tuning PI controller using Ziegler-Nichols method with signal input in fixed frequency and variable amplitude. The outputs which controlled are top end point composition $\left(\mathrm{Y}_{1}\right)$ and side end point composition $\left(\mathrm{Y}_{2}\right)$ of SHOF. The performance from the system was measured by using Integral Absolute Error (IAE).

\section{Methodology}

\subsection{Auto-tuning relay feedback controller}

The relay feedback auto-tuning method is the development of the second tuning method of Ziegler-Nichols, which uses the proportional gain value as the ultimate gain to obtain the oscillation graph output constantly replaced by ultimate gain value $\mathrm{K}_{\mathrm{u}}$ using relay. The block diagram of auto-tuning relay feedback as a control system is shown in Figure 1[7].

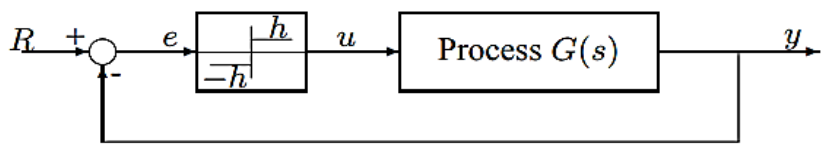

Fig. 1. Block diagram of auto-tuning relay feedback.

The basic principle of this method is the limitation period value of the oscillation process. It is controlled using a closed-loop method with a relay as a control system. The input and output signal obtained with the control signal (u) is shown in Figure 2[7].

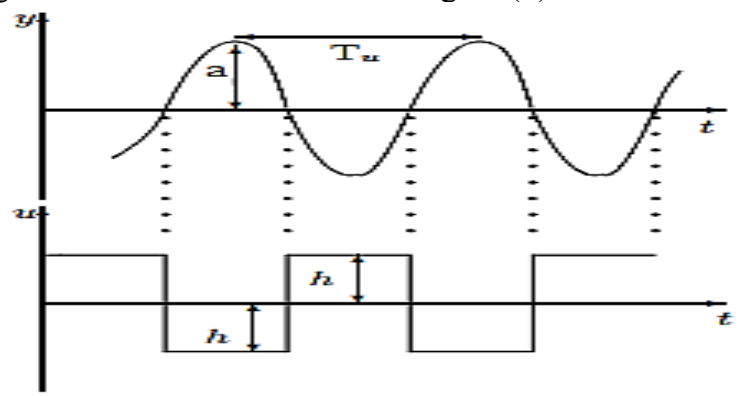

Fig. 2. Input and output of relay feedback system.

The input to the process $\mathrm{G}(\mathrm{s})$ is a square wave with the amplitude $\mathrm{h}$ and frequency $\omega_{\mathrm{u}}$. The output is a sinusoidal with the amplitude $4 \mathrm{~d} / \pi$. Relation of the input and output of the process is shown in equation 1.

$$
a=\frac{4 h}{\pi}\left|G\left(j \omega_{u}\right)\right|
$$

In order to have an oscillation, the fundamental component of the input and the output must be have the opposite phase. The conditions for oscillation are here,

$$
\arg G\left(j \omega_{u}\right)=-\pi
$$




$$
\left|G\left(j \omega_{u}\right)\right|=\frac{a \pi}{4 h}=\frac{1}{K u}
$$

where $\mathrm{Ku}$ is called the ultimate gain and can be regarded as the equivalent gain of the relay for transmission of sinusoidal signals with amplitude a and $\mathrm{Tu}$ is similarly called the ultimate period. The calculation of the PID control parameter with relay feedback is determined by the ultimate period and the ultimate gain as shown in Table 1[8].

Table 1. Ziegler-Nichols PID parameter according to the ultimate point.

\begin{tabular}{|c|c|c|c|}
\hline Controller & $\mathbf{K p}$ & $\mathbf{T i}$ & Td \\
\hline P & $0.5 \mathrm{Ku}$ & - & - \\
\hline PI & $0.4 \mathrm{Ku}$ & $0.8 \mathrm{Tu}$ & - \\
\hline PID & $0.6 \mathrm{Ku}$ & $0.5 \mathrm{Tu}$ & $0.12 \mathrm{Tu}$ \\
\hline
\end{tabular}

\subsection{Shell heavy oil fractionator}

The heavy oil fractionator is characterized by three outcomes draws and three sides circulating loops as shown in Figure 3[2].

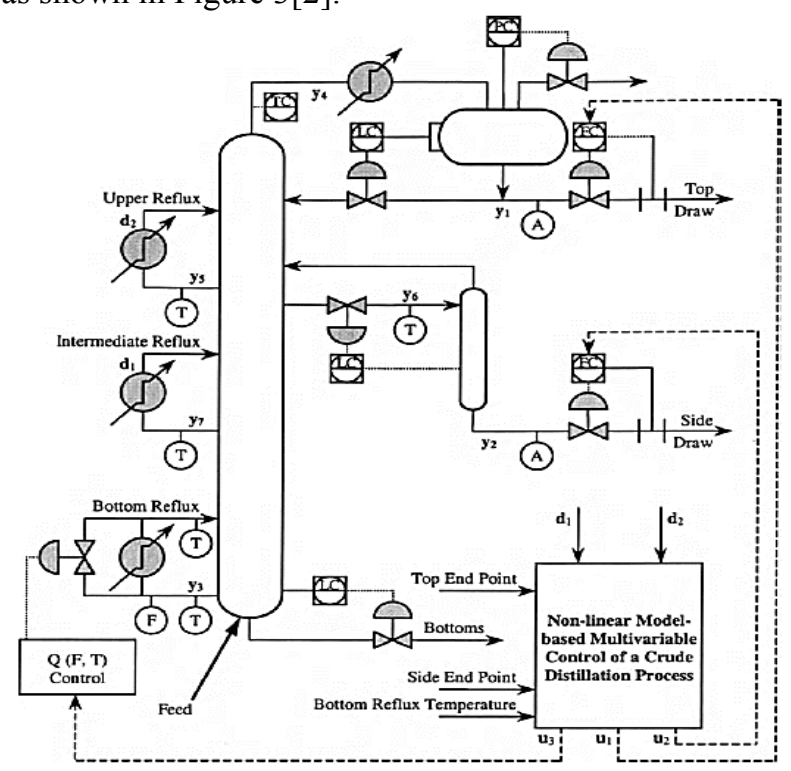

Fig.3. Shell heavy oil fractionator.

The transfer function of SHOF plant is shown in equation $(4)[1,2]$. SHOF is a multivariable system with three inputs and three outputs (MIMO). Interaction between subsystems is reduced by applying the method of Relative Gain Array (RGA) and decoupling, so the system can be transformed into three Single Input Single Output (SISO).

$$
\left[\begin{array}{l}
Y_{1} \\
Y_{2} \\
Y_{3}
\end{array}\right]=\left[\begin{array}{ccc}
\frac{4.05 e^{-27 s}}{50 s+1} & \frac{1.77 e^{-28 s}}{60 s+1} & \frac{5.88^{-27 s}}{50 s+1} \\
\frac{5.39^{-18 s}}{50 s+1} & \frac{5.72^{-14 s}}{60 s+1} & \frac{6.90^{-15 s}}{40 s+1} \\
\frac{4.38^{-20 s}}{33 s+1} & \frac{4.42^{-22 s}}{44 s+1} & \frac{7.20}{19 s+1}
\end{array}\right]\left[\begin{array}{l}
U_{1} \\
U_{2} \\
U_{3}
\end{array}\right]+\left[\begin{array}{cc}
\frac{1.20 e^{-27 s}}{45 s+1} & \frac{1.44 e^{-27 s}}{40 s+1} \\
\frac{1.52 e^{-15 s}}{25 s+1} & \frac{1.83 e^{-15 s}}{20 s+1} \\
\frac{1.14}{27 s+1} & \frac{1.26}{32 s+1}
\end{array}\right]\left[\begin{array}{l}
d_{1} \\
d_{2}
\end{array}\right]
$$

The RGA was used to determine the best input manipulative-output controller pairing and can be calculated from the expression here [9]

$$
\Lambda=K_{i j} \otimes H_{i j}=K \otimes\left(K^{-1}\right)^{T}
$$


where $\otimes$ denotes the Schur product (element by element multiplication):

$$
K_{i j} \otimes H_{i j}=K_{i j} H_{i j}
$$

The value of RGA that obtained with equation (5) and determinate pairing rule, with the paired elements along the diagonal and avoid pairings that correspond to negative steadystate RGA-elements[10], so can be determined the controlled output pair of the best manipulative input for multivariable control leads to a so-called dominant interaction strategy[11].

\subsection{Design of auto-tuning relay feedback Ziegler Nichols}

Design of auto-tuning relay feedback method has two steps. Step one, make the SHOF system on top end point composition $\left(\mathrm{Y}_{1}\right)$ and side end point composition $\left(\mathrm{Y}_{2}\right)$ in close loop circuit using relay. The magnitude of the relay is added from 0 until a critical magnitude relay is obtained to get a graph of the constant of amplitude and the period oscillation ouput process. The graph of each output can be seen in Figure 4.

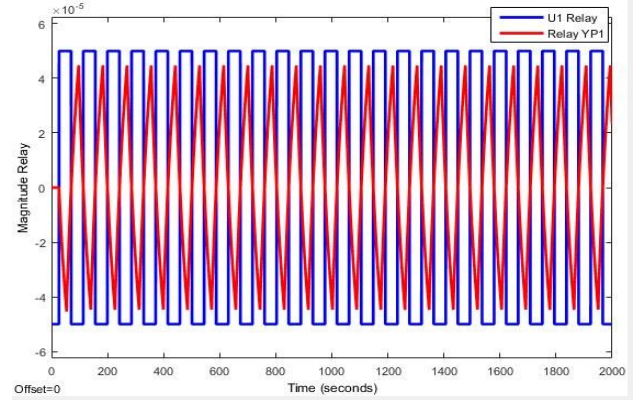

(a). output $\mathrm{Y} 1$

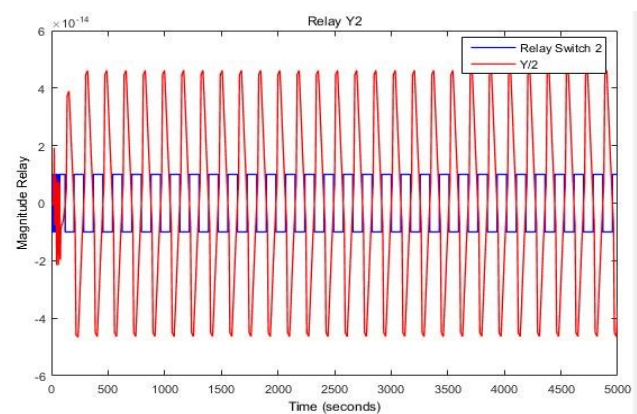

(b). output Y2

Fig. 4. Magnitude and period oscillation relay feedback.

Based on Figure 4, the values of $h, a$ and $T_{u}$ at top end point composition $\left(\mathrm{Y}_{1}\right)$ are respectively $6 \times 10^{-15}, 7.11 \times 10^{-14}$, and 80.85305 also the values of side end point composition $\left(\mathrm{Y}_{2}\right)$ the values of $\mathrm{h}, \mathrm{a}$, and $\mathrm{T}_{\mathrm{u}}$ is $4 \times 10^{-5}, 4.3306 \times 10^{-5}$, and 50.3283 respectively. Step two, looking for the values of $\mathrm{K}_{\mathrm{u}}, \mathrm{K}_{\mathrm{p}}$, and $\mathrm{K}_{\mathrm{i}} \cdot \mathrm{K}_{\mathrm{u}}$ is obtained by using equation (3), while $K_{p}$ and $K_{i}$ using the equation PI Ziegler Nichols in Table 1.

\section{Result}

\subsection{The response without disturbance}

The set point of top end point composition $\left(\mathrm{Y}_{1}\right)$ increase test from 0.0 to +0.5 ; response system is shown in Figure 5. Figure 5a shows that auto-tuning relay feedback ZieglerNichols controller is capable to reach set point value and steady state of top end point composition $\left(\mathrm{Y}_{1}\right)$ and capable to maintain the initial set point value of side end point composition $\left(\mathrm{Y}_{2}\right)$, also PI controller is capable to maintain the initial set point value of bottom reflux temperature $\left(\mathrm{Y}_{3}\right)$. Based on Figure $5 \mathrm{~b}$, flow rate on top draw $\left(\mathrm{u}_{1}\right)$, side draw $\left(\mathrm{u}_{2}\right)$, and bottom reflux duty $\left(\mathrm{u}_{3}\right)$ gave a graph result are within high and low limits of 0.5 and -0.5 . The IAE value in this test is obtained by auto-tuning relay feedback Ziegler Nichols controller at top end point composition $\left(\mathrm{Y}_{1}\right)$, and side end point composition $\left(\mathrm{Y}_{2}\right)$ with 31.06 and 6.13 , respectively and by PI controller at bottom reflux temperature $\left(\mathrm{Y}_{3}\right)$ with 0.04 . 
The set point of side end point composition $\left(\mathrm{Y}_{2}\right)$ is the increase test from 0.0 to +0.5 ; response system is viewed in Figure 6. Auto-tuning relay feedback Ziegler-Nichols controller is capable to reach set point value and steady state of side end point composition $\left(\mathrm{Y}_{2}\right)$ and capableto maintain the initial set point value of top end point composition $\left(\mathrm{Y}_{1}\right)$. Flow rate on top draw $\left(u_{1}\right)$, side draw $\left(u_{2}\right)$, and bottom reflux duty $\left(u_{3}\right)$ gave a graph result are within high and low limits of 0.5 and -0.5 . The IAE value in this test is obtained by auto-tuning relay feedback Ziegler Nichols controller at top end point composition $\left(\mathrm{Y}_{1}\right)$, and side end point composition $\left(\mathrm{Y}_{2}\right)$ with 1.22 and 100.47, and by PI controller at bottom reflux temperature $\left(\mathrm{Y}_{3}\right)$ with 0.06 .

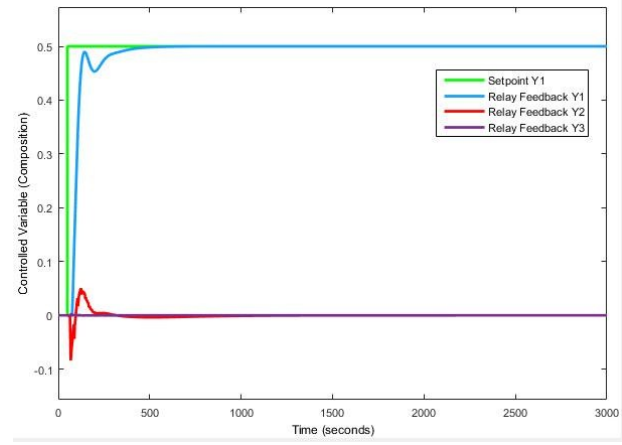

(a). Output SHOF response

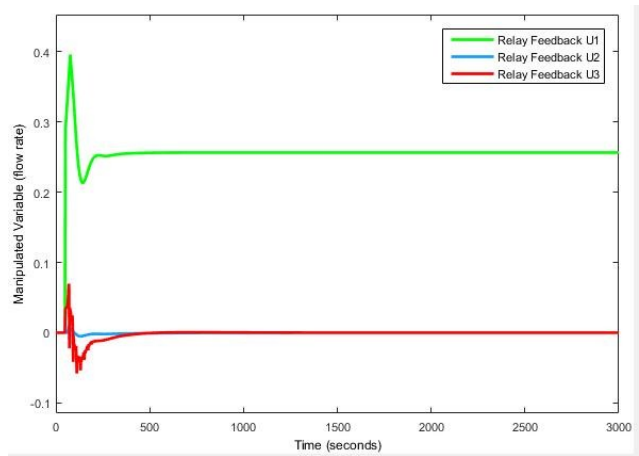

(b). Input SHOF response

Fig. 5. SHOF response to the increase of top end point composition $\left(\mathrm{Y}_{1}\right)+0.5$

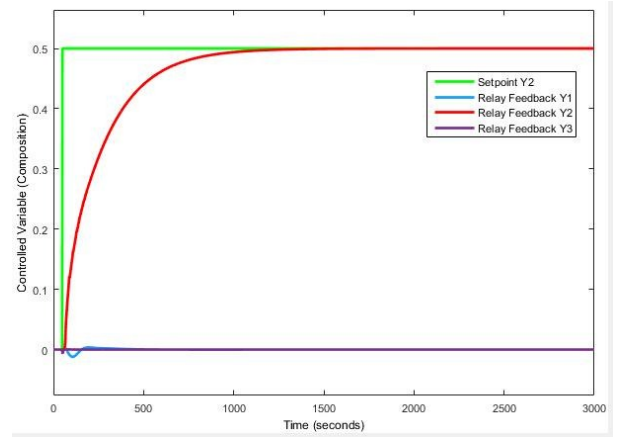

(a). Output SHOF response.

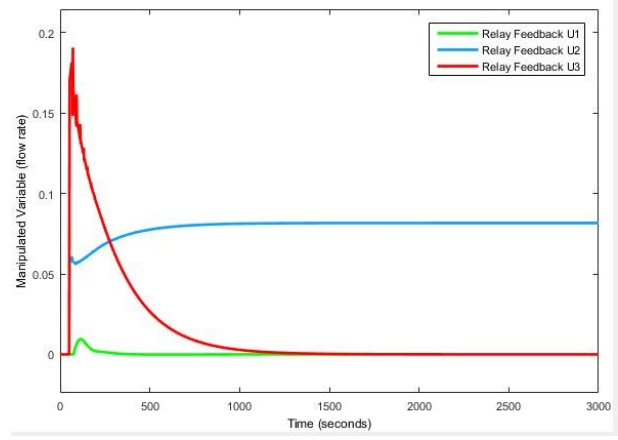

(b). Input SHOF response

Fig. 6. SHOF response to the increase of side end point composition $\left(\mathrm{Y}_{2}\right)+0.5$

\subsection{The response with disturbance}

The step input and output of intermediate reflux duty $\left(\mathrm{d}_{1}\right)$ and upper reflux duty $\left(\mathrm{d}_{2}\right)$ by +0.5 are shown in Figure 7. 


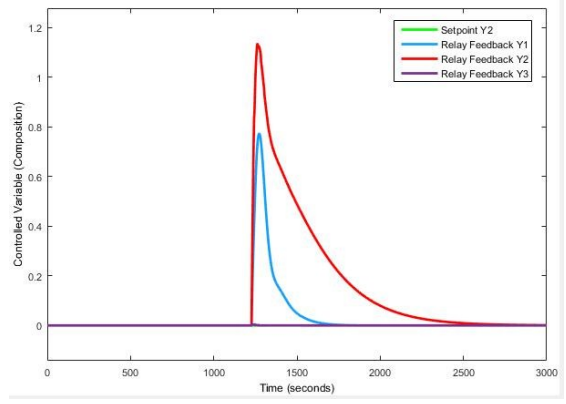

(a). Output SHOF response

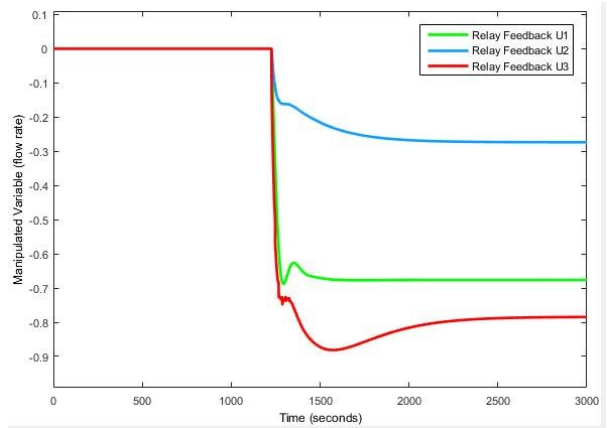

(b). Input SHOF response

Fig. 7. SHOF response with input disturbance +0.5 .

PI controller is capable to eliminate the disturbance which is the step input of intermediate reflux duty $\left(\mathrm{d}_{1}\right)$ and upper reflux duty $\left(\mathrm{d}_{2}\right)$ by +0.5 and capable to maintain the initial set point value and the initial steady-state condition of each product composition $\left(\mathrm{Y}_{1}, \mathrm{Y}_{2}\right.$, and $\mathrm{Y}_{3}$ ). The IAE value in this test is obtained by auto-tuning relay feedback Ziegler-Nichols controller at top end point composition $\left(\mathrm{Y}_{1}\right)$, and side end point composition $\left(\mathrm{Y}_{2}\right)$ with 83.17 and 336.38 respectively, and by PI controller at bottom reflux temperature $\left(\mathrm{Y}_{3}\right)$ with 0.15 .

\section{Conclusion}

Based on all test results, the auto-tuning relay feedback controller using Ziegler-Nichols tuning method was able to eliminate the disturbance in the Shell heavy oil fractionator and able to control the system to maintain initial set point value and initial steady-state condition as well as achieving new set point value and new steady-state condition. The average IAE value with auto-tuning relay feedback controller at top end point composition $\left(\mathrm{Y}_{1}\right)$ obtained with disturbance and no disturbance of 83.17 and 10.933 , at side end point composition $\left(\mathrm{Y}_{2}\right)$ obtained with disturbance and no disturbance of 336.38 and 42.3467 , and with PI controller at bottom reflux temperature $\left(\mathrm{Y}_{3}\right)$ obtained with disturbance and no disturbance of 0.15 and 0.13 .

\section{References}

1. C. E. García, D. M. Prett, and B. L. Ramaker, Fundamental Process Control, 1st ed. Boston: Butterworths, (1988).

2. R. M. Ansari and M. O. Tadé, Nonlinear Model-based Process Control Applications in Petroleum Refining, 1st ed. London: Springer, (2000).

3. H. Pan and H. Gao, "A combinatory study on MPC with subspace identification, steady-state target calculation and dynamic quadratic control," Proc. World Congr. Intell. Control Autom., vol. 2015-March, no. March, pp. 3164-3169, (2015).

4. C. Huang and S. Chen, "Performance assessment of process with uncertainties based on minimum variance *," no. Iccse, pp. 848-854, (2016).

5. K. Bijeesh, D. Kalpana, and T. Thyagarajan, "Identification of 3-by-3 MIMO system using relay feedback," Proc. 2014 IEEE Int. Conf. Adv. Commun. Control Comput. Technol. ICACCCT 2014, no. 978, pp. 157-162, (2015).

6. D. Kalpana, T. Thyagarajan, and N. Venkatachalam, "Design of fractional order PI 
controller for MIMO system using relay feedback," Proc. - TIMA 2017 9th Int. Conf. Trends Ind. Meas. Autom., (2017).

7. C.-C. Yu, Auto-tuning of PID controllers - A Relay Feedback Approach, 2nd ed., vol. 11, no. 1. Taiwan: Springer, (2001).

8. K. J. Åström and B. Wittenmark, Adaptive Control. New York: Dover Publications, Inc., (2008).

9. D. E. Seborg, T. F. Edgar, and D. A. Mellichamp, Process Dynamics and Control, 2nd ed. United States of America: John Wiley \& Sons, Inc, (2004).

10. S. Skogestad and I. Postlethwaite, Multivariable feedback control: analysis and design, 2nd ed., vol. 8, no. 14. New York: John Wiley \& Sons, Inc, (2005).

11. M. T. Tham, "Multivariable control: An Introduction to Decoupling Control," Univ. Newcastle upon Tyne, Newcastle upon Tyne, vol. 1999, no. May, (1999). 